\title{
Automated mass spectrometric analysis of urinary and plasma serotonin
}

\author{
Wilhelmina H. A. de Jong • Marianne H. L. I. Wilkens • \\ Elisabeth G. E. de Vries • Ido P. Kema
}

Received: 22 September 2009 /Revised: 9 November 2009 / Accepted: 8 January 2010 /Published online: 7 February 2010

(C) The Author(s) 2010. This article is published with open access at Springerlink.com

\begin{abstract}
Serotonin emerges as crucial neurotransmitter and hormone in a growing number of different physiologic processes. Besides extensive serotonin production previously noted in patients with metastatic carcinoid tumors, serotonin now is implicated in liver cell regeneration and bone formation. The aim was to develop a rapid, sensitive, and highly selective automated on-line solid-phase extraction method coupled to high-performance liquid chromatography-tandem mass spectrometry (XLC-MS/MS) to quantify low serotonin concentrations in matrices such as platelet-poor plasma and urine. Fifty microliters plasma or $2.5 \mu \mathrm{L}$ urine equivalent were pre-purified by automated on-line solid-phase extraction, using weak cation exchange. Chromatography of serotonin and its deuterated internal standard was performed with hydrophilic interaction chromatography. Mass spectrometric detection was operated in multiple reaction monitoring mode using a quadrupole tandem mass spectrometer with positive electrospray ionization. Serotonin concentrations were determined in platelet-poor plasma of metastatic carcinoid patients $(n=23)$ and healthy controls $(n=22)$. Urinary reference intervals were set by analyzing 24 -h urine collections of 120 healthy subjects. Total run-time was 6 min. Intra- and inter-assay analytical variation were $<10 \%$. Linearity in the $0-7300 \mu \mathrm{mol} / \mathrm{L}$ calibration range was excellent $\left(\mathrm{R}^{2}>0.99\right)$. Quantification limits were 30 and
\end{abstract}

W. H. A. de Jong • M. H. L. I. Wilkens • I. P. Kema ( $\square)$ Department of Laboratory Medicine, University Medical Center, Groningen, University of Groningen,

P.O. Box 30001, 9700 RB Groningen, The Netherlands

e-mail: i.p.kema@lc.umcg.nl

E. G. E. de Vries

Department of Medical Oncology, University Medical Center,

Groningen, University of Groningen,

9700 RB Groningen, The Netherlands
$0.9 \mathrm{nmol} / \mathrm{L}$ in urine and plasma, respectively. Platelet-poor serotonin concentrations in metastatic carcinoid patients were significantly higher than in controls. The urinary reference interval was $10-78 \mu \mathrm{mol} / \mathrm{mol}$ creatinine. Serotonin analysis with sensitive and specific XLC-MS/MS overcomes limitations of conventional HPLC. This enables accurate quantification of serotonin for both routine diagnostic procedures and research in serotonin-related disorders.

Keywords Serotonin · 5-hydroxytryptamine $\cdot$ LC-MS/MS . On-line SPE $\cdot$ Mass spectrometry $\cdot$ Automation
Abbreviations
5-HT 5-Hydroxytryptamine (serotonin)
XLC-MS/ On-line solid-phase extraction-high-performance
MS liquid chromatography-tandem mass spectrometry
SPE Solid-phase extraction
HPLC High-performance liquid chromatography
MS/MS Tandem mass spectrometry
5-HT- $d_{4} \quad$ Deuterium-labeled serotonin

\section{Introduction}

Serotonin (5-HT: 5-hydroxytryptamine) is synthesized from the essential amino acid tryptophan in the enterochromaffin cells of the gut and in serotonergic neurons in the central nervous system. The major part of dietary tryptophan is used for protein synthesis, while about $2 \%$ of the dietary tryptophan is used for the serotonin production. Serotonin is stored predominantly (about $80 \%$ ) in the enterochromaffin cells of the gastrointestinal tract, in the dense granules of platelets and in the serotonergic neurons of the central nervous system [13]. Peripheral serotonin is metabolized mainly in the lung 
and the liver via enzymatic conversion by monoamine oxidase-A (MAO-A; EC 1.4.3.4), resulting in urinary excretion of 5-hydroxyindole-3-acetic acid (5-HIAA) [3].

Serotonin is a neurotransmitter involved in CNS neurotransmission processes, but also emerges as a crucial hormone in a growing number of different physiologic processes outside the brain. Depletion of serotonin is implicated in liver cell regeneration [4], bone formation and psychiatric diseases [5-8], while extensive serotonin production has been noted in carcinoid tumors $[5,9,10]$. Depending on the site of origin, carcinoid tumors can give rise to excessive synthesis, storage, and release of serotonin; its precursor, 5-hydroxytryptophan (5-HTP); and its major metabolite, 5-HIAA. For the clinical chemical diagnosis and follow-up of patients with carcinoid tumors, measurements of serotonin, its precursors and its metabolites in body fluids and tissues are used.

In previous studies, we showed that platelet serotonin is the most accurate marker for the diagnosis of carcinoids $[11,12]$. In healthy subjects, but not in carcinoid patients, $99 \%$ of circulatory serotonin is accumulated and stored in platelets. Therefore, the measurement of the free serotonin concentration in platelet-poor plasma might provide information about the level of serotonin overproduction which is of clinical relevance for carcinoid patients, since the free fraction is the serotonin pool that actually binds to the serotonin receptor and exerts its actions.

Normally, circulating serotonin is almost entirely confined to platelets. Due to its low concentrations and the resulting analytical detectability problems, free plasma serotonin has not been measured routinely. 5-HIAA in urine is used for follow-up of carcinoid patients. It reflects best the tumor burden as it is the metabolic end product resulting from free and stored serotonin turnover. Urinary serotonin is less important, but is considered to reflect clearance of plasma free serotonin and renal decarboxylated 5-hydroxytryptophan (5-HTP) [13, 14]. Quantification can however be useful in the diagnosis of midgut and aromatic amino acid decarboxlyase (AADC)-deficient foregut carcinoids [9, 11, 13, 15]. In previous studies, it was noted that some of these tumors cannot produce serotonin, because of a deficiency in the enzyme AADC responsible for the conversion of 5-HTP to serotonin. In these cases, some 5-HTP can be decarboxylated by the kidney and thus excreted in the urine as serotonin. Urinary serotonin measurement was therefore considered to be a useful marker in the diagnosis of AADC-deficient carcinoid [13].

Several analytical techniques have been developed for the measurement of serotonin and its related compounds. HPLCbased techniques are commonly used [12, 16] and easily coupled to mass spectrometric detectors to increase analytical sensitivity and specificity and reduce the chance of interferences. In addition, automation of sample pre-treatment is emerging [17, 18], since it enables the reduction of analytical variation attributable to differences in manual sample pretreatment and, moreover, decreases analysis turnaround time.

In order to enable quantification of serotonin in plateletpoor plasma and to replace the laborious, currently used method for urinary serotonin, we developed an automated on-line solid-phase extraction-liquid chromatographic method with tandem mass spectrometric detection (XLCMS/MS) for the measurement of serotonin. This method combines selective and specific liquid chromatographictandem mass spectrometry with on-line solid-phase extraction (SPE) and uses similar analytical principles as previously described for plasma metanephrines analysis [19]. With this technique, we quantified plasma free serotonin in 22 healthy controls and 23 carcinoid patients and established the reference interval for urinary serotonin excretion in 24-h urine collections in 120 healthy subjects.

\section{Experimental}

\section{Chemicals and reagents}

HPLC-grade acetonitrile was obtained from Rathburn Chemicals Ltd. (Walkerburn, UK); ammonium formate $99.995^{+} \%$ from Sigma-Aldrich Ltd. (Steinheim, Germany); formic acid $98 \%$ to $100 \%$ ultrapure from BDH Laboratory Supplies (Poole, UK); sodium hydroxide $(\mathrm{NaOH})$, hydrochloric acid and urine preservatives ascorbic acid and EDTA were acquired from Merck KGaA (Darmstadt, Germany).

Serotonin was purchased from Sigma-Aldrich Ltd. and serotonine- $\alpha, \alpha, \beta, \beta-\mathrm{d} 4$ creatinine sulfate complex from $\mathrm{C} / \mathrm{D} / \mathrm{N}$ Isotopes Inc. (Pointe-Claire, Quebec, Canada); Reagent-grade water, obtained from a Barnstead system, was used throughout the study procedure. All chemicals and solvents were of analytical-reagent-grade.

\section{Instruments}

A Spark Holland Symbiosis ${ }^{\circledR}$ on-line SPE system (Spark Holland, Emmen, the Netherlands) was used for all analyses. The system consists of a temperature-controlled autosampler (temperature maintained at $10{ }^{\circ} \mathrm{C}$ ), a SPE controller unit (automated cartridge exchanger or ACE), a solvent delivery unit (two high-pressure dispensers), and an HPLC pump, as shown previously $[19,20]$. The ACE module contains two connectable six-way valves and a SPE cartridge-exchange module. The high-pressure dispensers provide SPE cartridges with solvents for conditioning, equilibration, sample application, and clean-up. The integrated HPLC pump was a binary high-pressure gradient pump. Column temperature was controlled with a Mistral Column Oven (Spark Holland). Detection was performed with a Quattro ${ }^{\circledR}$ Premier 
tandem mass spectrometer equipped with a $\mathrm{Z}$ Spray $^{\circledR}$ ion source operated in positive electrospray ionization mode (Waters, Milford, MA). All aspects of system operation and data acquisition were controlled using MassLynx v4.1 software with automated data processing using the QuanLynx Application Manager (Waters).

\section{Biological samples}

For method-comparison studies, urine samples with a concentration range up to $4,240 \mu \mathrm{mol} / \mathrm{L}$ were used from 60 patients with suspected or known metastatic carcinoid tumors. The reference interval for urinary free serotonin was obtained from the analysis of 24-h urine collections of 120 healthy subjects, participating in the LifeLines study (24). The reference interval was calculated with EP Evaluator ${ }^{\mathrm{TM}}$ software [21] as recommended by the Clinical and Laboratory Standards Institute (CLSI) according to CLSI C28-A2 [22]. LifeLines is a multi-disciplinary prospective population-based cohort study examining in a unique threegeneration design the health and health-related behaviors of 165,000 persons living in the North East region of The Netherlands. It employs a broad range of investigative procedures in assessing the biomedical, socio-demographic, behavioral, physical, and psychological factors which contribute to the health and disease of the general population, with a special focus on multimorbidity. In addition, the LifeLines project comprises a number of cross-sectional substudies which investigate specific age-related conditions. These include investigations into metabolic and hormonal diseases, including obesity, cardiovascular and renal diseases, pulmonary diseases and allergy, cognitive function and depression, and musculoskeletal conditions.

Plasma free serotonin levels were determined in a prospective pilot study of 22 healthy controls and 15 patients with a metastatic serotonin-producing carcinoid tumor [23], which was extended with eight patients to a total of 23 carcinoid patients. Blood for platelet-poor plasma was obtained by venipuncture using a butterfly needle to collect in $5 \mathrm{~mL}$ plastic syringes containing $60 \mu \mathrm{L}$ $7.5 \% \quad \mathrm{~K}_{3}$ EDTA solution. Blood was centrifuged within $30 \mathrm{~min}$ after drawing at $12,000 \times \mathrm{g}$ for $2 \mathrm{~min}$ in an Eppendorf Microcentrifuge at $22{ }^{\circ} \mathrm{C}$ [24]. The remaining plasma was stored at $-80{ }^{\circ} \mathrm{C}$ until analysis. The studies were approved by the medical ethical committee of our institution and conducted in accordance with the guidelines of the Declaration of Helsinki. All participants gave written informed consent.

\section{Sample preparation}

Working solutions of serotonin were diluted from a freshly weighed stock solution $(1 \mathrm{mg} / \mathrm{mL})$ on the day of analysis.
Working solutions of serotonin- $d_{4}(1 \mu \mathrm{M})$ were diluted from the stock solution $(0.4 \mathrm{mg} / \mathrm{mL}$ in $0.04 \mathrm{M}$ ascorbic acid $)$ that was stored at $-20^{\circ} \mathrm{C}$ for 6 months. Aqueous calibrators were prepared by addition of working solution corresponding to concentrations from 30 to $7,300 \mathrm{nmol} / \mathrm{L}$ serotonin for urinary analysis and from 3.49 to $4900 \mathrm{nmol} / \mathrm{L}$ for plasma. All solutions were prepared in water with ascorbic acid added as preservative $(400 \mathrm{mg} / \mathrm{L})$. Urinary calibration curves were aqueous. Plasma calibration curves were made using blank plasma, obtained by dialysis. Low, medium, and high quality-control samples were made by pooling urine and plasma from healthy subjects and carcinoid patients for diagnostic procedures available at our laboratory. Urine samples were stored at $-20{ }^{\circ} \mathrm{C}$ until analysis, platelet-poor plasma samples at $-80^{\circ} \mathrm{C}$.

Fifty microliters of urine (acidified with $\mathrm{HCl}$ to $\mathrm{pH} 4$ and containing the conservatives ascorbic acid and EDTA (1:1 $w / w)$, added prior to collection) or $500 \mu \mathrm{L}$ of plasma was mixed directly in an autosampler vial with $100 \mu \mathrm{L}$ internal standard solution (final concentration $1800 \mathrm{nmol} / \mathrm{L}$ for urine and $80 \mathrm{nmol} / \mathrm{L}$ for plasma). Urine samples were diluted with $0.2 \mathrm{M}$ phosphate buffer ( $\mathrm{pH} 7)$ in ascorbic acid solution and plasma samples with ascorbic acid solution to reach a final volume of $1 \mathrm{~mL}$. Fifty microliters (urine sample) or $100 \mu \mathrm{L}$ (plasma) was injected into the XLC-MS/MS system. This injection volume was equivalent to $2.5 \mu \mathrm{L}$ of urine and $50 \mu \mathrm{L}$ plasma.

\section{On-line SPE}

Sample clean-up took place by on-line SPE, following a similar procedure as described previously for the structure related metanephrines [19]. Oasis ${ }^{\circledR}$ WCX (weak cation exchange) 10 by $1 \mathrm{~mm}$ SPE cartridges (Waters Corp.) were used for sample extraction. The Symbiosis ${ }^{\circledR}$ system was designed to proceed automatically through a series of programmable routines during which the SPE cartridge is loaded, washed, and eluted by solvents delivered by two high-pressure dispensers (HPD1 and HPD2). Serotonin was eluted directly on the analytical column by LC gradient elution ( $600 \mu \mathrm{L}$ of mobile phase). Processing of subsequent samples was carried out in parallel and cartridges were regenerated.

\section{Liquid chromatography}

Chromatographic separation was achieved by using an Atlantis HILIC Silica column (particle size $3 \mu \mathrm{m}, 2.1 \mathrm{~mm}$ internal diameter by $50 \mathrm{~mm}$; Waters). A gradient flow of $100 \mathrm{mmol} / \mathrm{L}$ ammonium formate in water adjusted to $\mathrm{pH} 3.0$ with formic acid (A) and acetonitrile (B; flow rate $0.40 \mathrm{~mL} / \mathrm{min}$ ) was applied to the chromatographic column (Table 1). Gradients applied were linear. Column temperature was kept at $25{ }^{\circ} \mathrm{C}$. 
Table 1 Gradient elution scheme liquid chromatography

\begin{tabular}{lccc}
\hline Time (mm:ss) & Flow (mL/min) & Solvent A\% & Solvent B \% \\
\hline $00: 01$ & 0.30 & 5 & 95 \\
$01: 30$ & 0.30 & 20 & 80 \\
$03: 30$ & 0.30 & 20 & 80 \\
$04: 00$ & 0.30 & 5 & 95 \\
$06: 00$ & 0.30 & 5 & 95 \\
\hline
\end{tabular}

Solvent A $100 \mathrm{mM}$ ammonium formate $\mathrm{pH}$ 3, Solvent $B$ acetonitrile

Mass spectrometry

The mass spectrometer was directly coupled to the chromatographic column. In positive electrospray ionization mode, serotonin and its deuterated internal standard were protonated to produce ions at the form $[\mathrm{M}+\mathrm{H}]^{+}$, with $\mathrm{m} / \mathrm{z} 177$ and $\mathrm{m} / \mathrm{z}$ 181, respectively. Upon collision-induced dissociation (CID) with argon gas, these precursor ions produced characteristic product ions of $m / z 160\left[\mathrm{M}-\mathrm{NH}_{2}\right]$ and $132\left[\mathrm{M}-\mathrm{C}_{2} \mathrm{H}_{4} \mathrm{NH}_{2}\right]$ and $115\left[\mathrm{M}-\mathrm{C}_{2} \mathrm{H}_{4} \mathrm{NH}_{2} \mathrm{OH}\right]$ for serotonin and $\mathrm{m} / \mathrm{z} 164,136$, and 119 for the deuterated internal standard. A multiple reaction monitoring mode (MRM) was developed for the specific $\mathrm{m} / \mathrm{z}$ transitions $177 \rightarrow 160, \quad 177 \rightarrow 132$ and $177 \rightarrow 115$ (serotonin) and
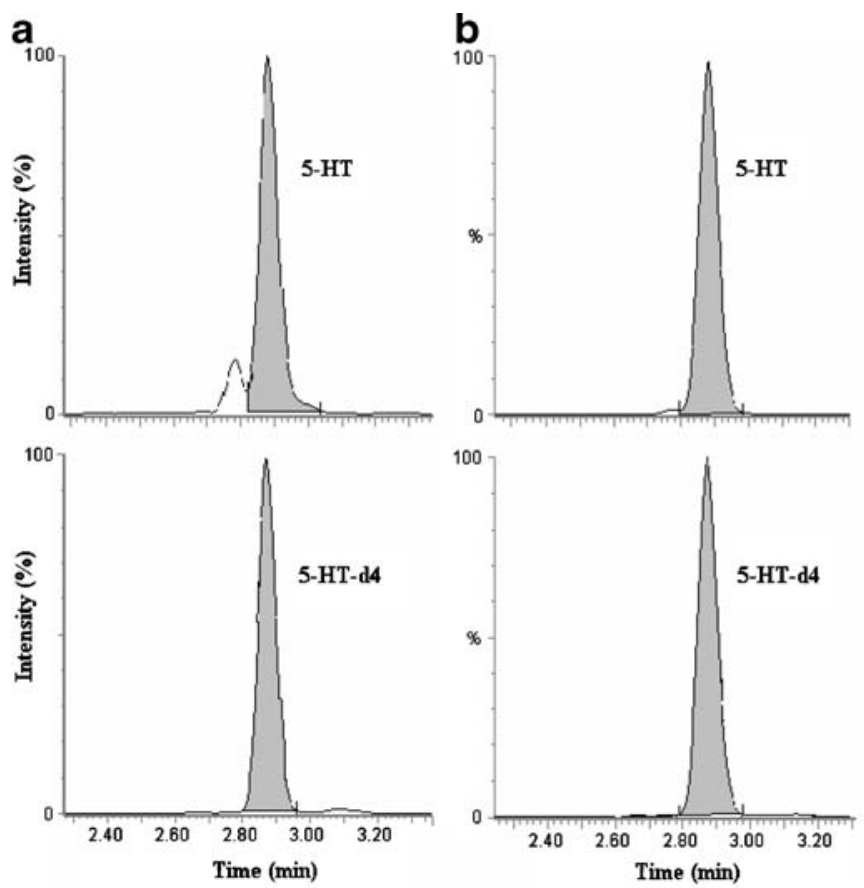

Fig. 1 Chromatograms of serotonin in urine and plasma samples from healthy controls and carcinoid patients, obtained by XLC-MS/MS analysis. Chromatograms are obtained by on-line solid-phase extraction using weak cation exchange coupled to hydrophilic interaction liquid chromatography with tandem mass spectrometric detection. The mass chromatograms show the mass transitions of $177 \rightarrow 160(5-\mathrm{HT})$ and $181 \rightarrow 164$ (deuterated internal standard $\left.5-\mathrm{HT}-\mathrm{d}_{4}\right)$. Retention time
$181 \rightarrow 164, \quad 181 \rightarrow 136$ and $181 \rightarrow 119$ (internal standard) using a dwell time of $0.05 \mathrm{~s}$ and an interchannel delay of $20 \mathrm{~ms}$. The second and third mass transitions were used as qualifiers, following EU directive 2002/657/EC.

\section{Statistics}

For method comparison of the urinary serotonin, Deming regression analysis was applied.

Student's $T$ test was applied for comparison of mean platelet-poor plasma serotonin levels in healthy controls and carcinoid patients (SPSS version 14).

\section{Results}

\section{Chromatography}

Total cycle time per sample, including extraction, was $6 \mathrm{~min}$. Serotonin and its deuterated internal standard coeluted after $2.8 \mathrm{~min}$. The identity of the compound was confirmed by the specific mass spectrum. In Fig. 1 mass chromatograms are shown of urine and platelet-poor plasma samples from a healthy subject (A and $\mathrm{C}$ ) and from a carcinoid patient (B and D). Ion suppression was examined
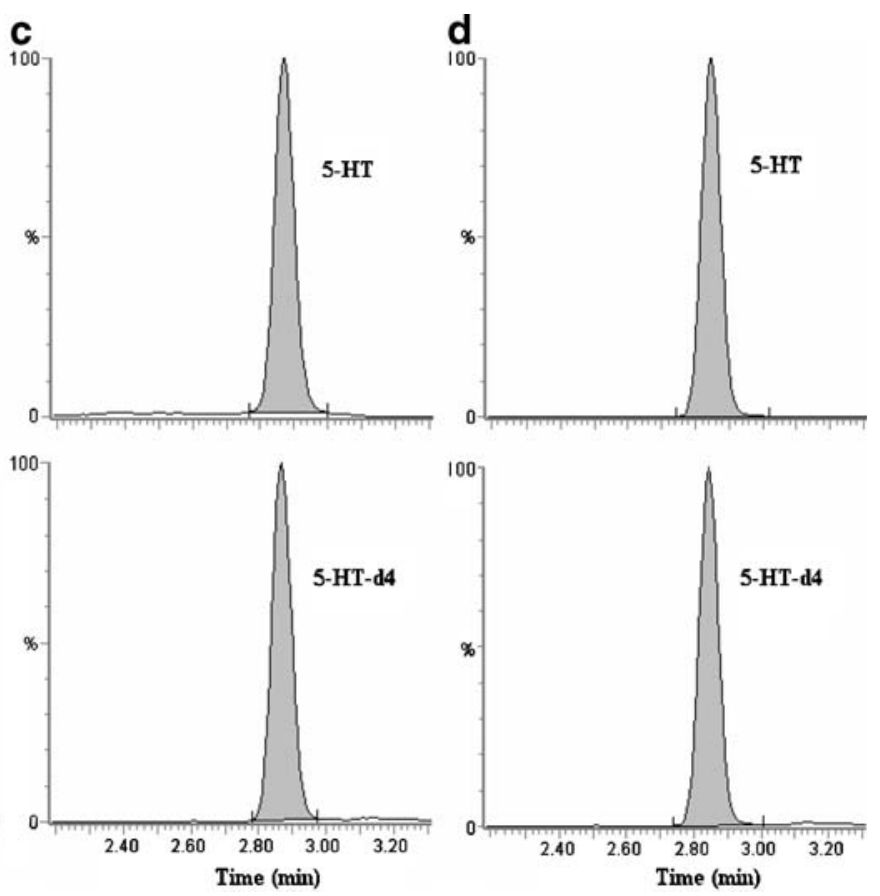

of serotonin is $2.8 \mathrm{~min}$. Responses are normalized to $100 \%$. a Urinary sample of a healthy control ( $32.4 \mu \mathrm{mol} / \mathrm{mol}$ creatinine), d0 area 8542 , $\mathrm{d} 4$ area 42163 . b Urinary sample of carcinoid patient $(718.5 \mu \mathrm{mol} / \mathrm{mol}$ creatinine), d0 area 541167, d4 area 81340. c Plasma sample of a healthy control $(4.2 \mathrm{nmol} / \mathrm{L})$, d0 area 5181, d4 area 73091. d Plasma sample of a carcinoid patient $(289.4 \mathrm{nmol} / \mathrm{L}), \mathrm{d} 0$ area $213186, \mathrm{~d} 4$ area 43549. 5-HT serotonin, 5-HT- $d_{4}$ deuterated serotonin 
by direct infusion of the analytes in the mass spectrometer with simultaneous injection of a blank sample and biological plasma and urine samples and was not observed for plasma or urine (data not shown).

\section{Detection limits}

The limit of quantification (S/N 10:1) was $0.03 \mu \mathrm{mol} / \mathrm{L}$ with a $\mathrm{CV}$ of $5.4 \%(n=20)$ in urine and $0.9 \mathrm{nmol} / \mathrm{L}$ with a CV of $9.0 \%(n=20)$ in plasma.

\section{Linearity and precision}

For urine analysis, aqueous calibration curves in a concentration range from $0.3-7300 \mu \mathrm{mol} / \mathrm{L}(n=8)$ showed excellent linearity. The mean slope was 0.4916 , intercept was $0.0075 \mu \mathrm{mol} / \mathrm{L}$ and correlation coefficient was 0.99 . Spiked urine calibration curve gave a comparable slope (0.4747), but a different intercept $(0.1145 \mu \mathrm{mol} / \mathrm{L})$, because of the endogen basal serotonin concentration present in pooled urine, which confirms the selectivity of the method.

Inter-assay linearity $(n=18)$ obtained over a concentration range from 3.5-4,900 $\mathrm{nmol} / \mathrm{L}$ serotonin in blank plasma was also excellent. The mean slope was 0.00165 , with no significant intercept and a correlation coefficient of 0.99. An aqueous calibration curve gave a comparable slope. Intra-assay precision was determined by replicate analyses in a single run at three concentrations $(n=20)$. Inter-assay was determined by analysis of three concentrations over 8 weeks $(n=20)$. For low, medium, and high concentrations in both urine and plasma CVs were $<10 \%$. Intra-assay CVs were $2.6-3.4 \%$ in urine and $1.6-7.5 \%$ in plasma. Inter-assay CVs were $2.8-10 \%$ in urine and $4.1-$
$7.9 \%$ in plasma. Precision data are shown in Table 2. Samples with high serotonin concentrations that exceed the calibration range can be diluted up to 50 times, which results in comparable outcomes.

Recovery and stability

Recovery experiments were conducted with spiked standard addition in three concentrations (low, medium, high) measured with and without solid-phase extraction. Recoveries ranged from $88-135 \%$ in both urine and plasma. Absolute recovery on the SPE cartridge was measured with spiked urine samples in the same concentration ranges. These recoveries ranged from $41-74 \%$ in plasma and 83 $85 \%$ in urine.

Samples, containing preservatives as described above, were found to be stable during three freeze-thaw cycles in both urine and plasma. Plasma samples were stable to a maximum of 2 days at $5{ }^{\circ} \mathrm{C}$ in the dark (autosampler), and urine samples for only $8 \mathrm{~h}$. Cartridges can be reused 3 times for urine samples and up to 15 times for plasma with consistent results and without occurrence of carry-over according to the EP10-A3 protocol of the Clinical and Laboratory Standards Institute [22].

\section{Biological samples}

The new XLC-MS/MS method correlated with the former conventional HPLC method [16] with a correlation coefficient of 0.9789 (Fig. 2). The regression equation for the XLC-MS/MS method (y) and the HPLC method $(x)$ had a slope of $1.093( \pm 0.059)$ and an intercept of 0.081 $( \pm 0.062) \mu \mathrm{mol}$.

Table 2 Intra- and inter-assay imprecision of serotonin analysis with XLC-MS/MS

\begin{tabular}{|c|c|c|c|c|c|c|c|c|c|c|}
\hline & \multicolumn{10}{|c|}{ Mean analytical variation in urine } \\
\hline & \multicolumn{5}{|c|}{ Intra-assay $(n=20)$} & \multicolumn{5}{|c|}{ Inter-assay $(n=15)$} \\
\hline & \multicolumn{2}{|l|}{ Mean } & \multicolumn{2}{|l|}{ SD } & \multirow[t]{2}{*}{ CV $(\%)$} & \multicolumn{2}{|l|}{ Mean } & \multicolumn{2}{|l|}{ SD } & \multirow[t]{2}{*}{$\mathrm{CV}(\%)$} \\
\hline & $\begin{array}{l}\text { ( } \mu \mathrm{mol} / \mathrm{mol} \\
\text { creatinine) }\end{array}$ & $(\mathrm{nmol} / \mathrm{L})$ & $\begin{array}{l}(\mu \mathrm{mol} / \mathrm{mol} \\
\text { creatinine) }\end{array}$ & $(\mathrm{nmol} / \mathrm{L})$ & & $\begin{array}{l}\text { ( } \mu \mathrm{mol} / \mathrm{mol} \\
\text { creatinine) }\end{array}$ & $(\mathrm{nmol} / \mathrm{L})$ & $\begin{array}{l}\text { ( } \mu \mathrm{mol} / \mathrm{mol} \\
\text { creatinine) }\end{array}$ & $(\mathrm{nmol} / \mathrm{L})$ & \\
\hline \multicolumn{11}{|l|}{ Urine } \\
\hline Low & 0.5 & & 0.01 & & 2.6 & 0.6 & & 0.06 & & 10.0 \\
\hline Medium & 2.1 & & 0.07 & & 3.3 & 1.9 & & 0.20 & & 9.9 \\
\hline High & 5.0 & & 0.20 & & 3.4 & 4.9 & & 0.14 & & 2.8 \\
\hline \multicolumn{11}{|l|}{ Plasma } \\
\hline Low & & 5.3 & & 0.40 & 7.5 & & 5.6 & & 0.44 & 7.9 \\
\hline Medium & & 174.2 & & 2.85 & 1.6 & & 165.9 & & 8.51 & 5.1 \\
\hline High & & 1120.9 & & 20.93 & 1.9 & & 1083.8 & & 44.9 & 4.1 \\
\hline
\end{tabular}

Analytical variation was calculated by measuring each sample 20 times per day (intra-assay) and in 20 different assays (inter-assay) 


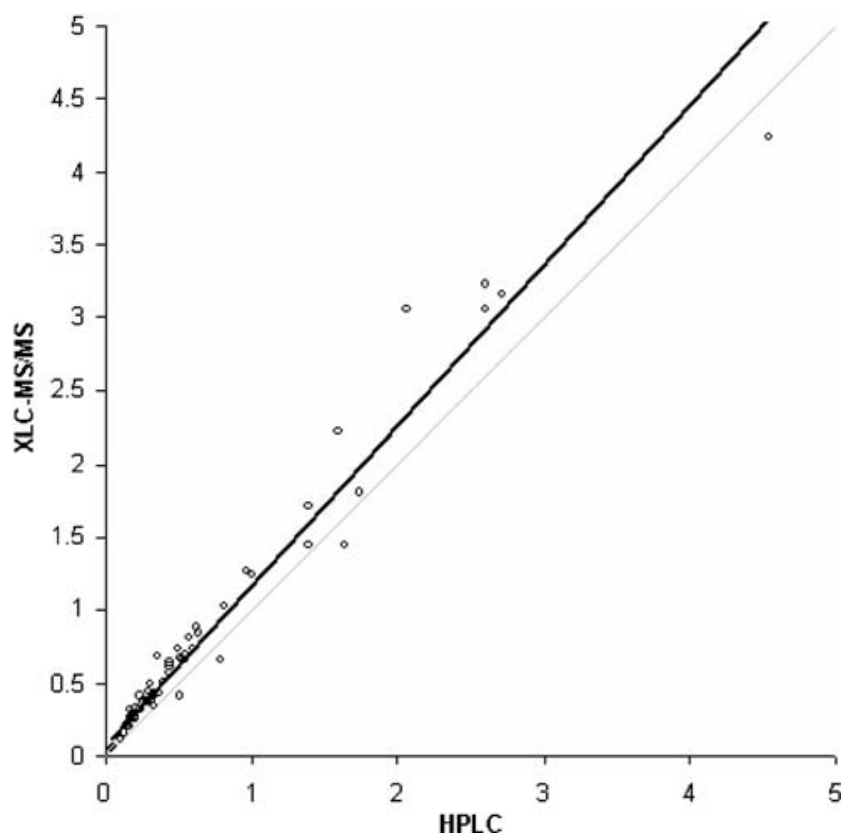

Fig. 2 Correlation between the new ( $y$ XLC-MS/MS) and the old ( $x$ HPLC-fluorometric detection) method for the measurement of serotonin in urine. The black line is the Deming regression scatter plot for the correlation between XLC-MS/MS and HPLC with equation $y=0.081+1.093 x$ and a correlation coefficient of 0.97 . The gray line shows the ideal correlation between the two methods with the equation $y=x$

The distribution of urinary serotonin concentrations in the 120 healthy subjects was normal (Fig. 3) and the reference interval was $10-78 \mu \mathrm{mol} / \mathrm{mol}$ creatinine.

Free plasma serotonin concentrations were significantly higher in carcinoid patients (mean concentration $60.8 \mathrm{nmol} / \mathrm{L}$ ) than in healthy controls (mean concentration $4.6 \mathrm{nmol} / \mathrm{L})(P<$ 0.001; Fig. 4).

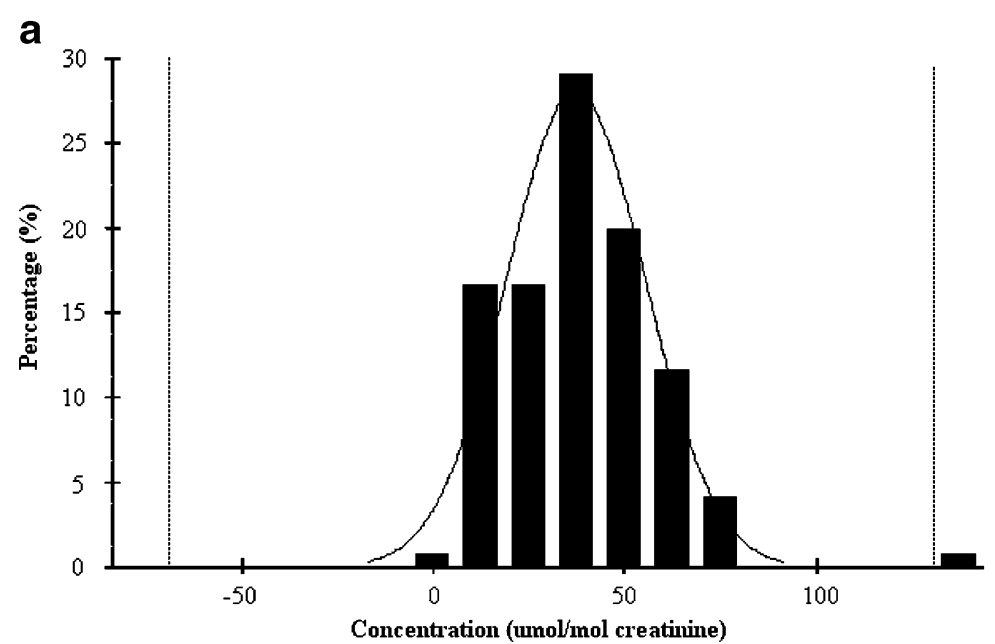

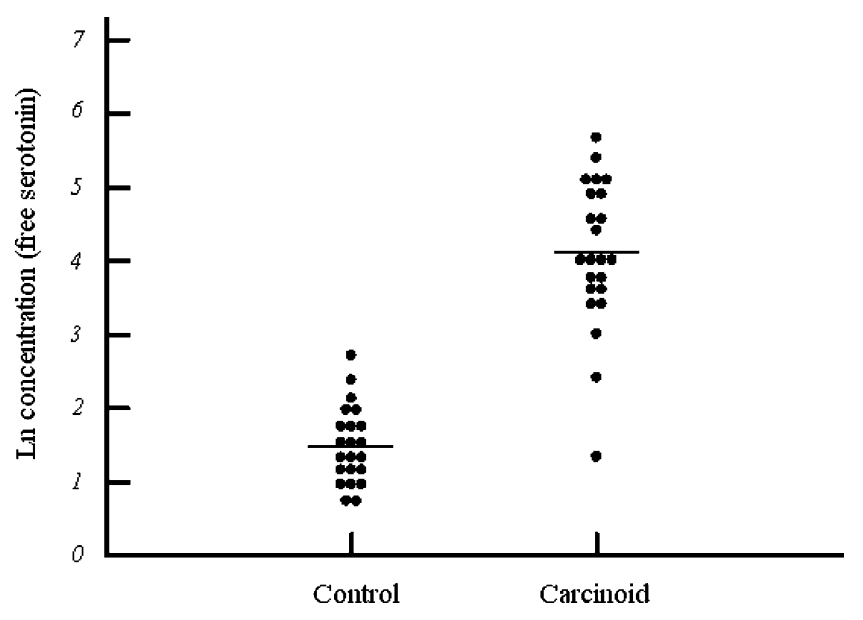

Fig. 4 Free serotonin concentrations in healthy controls $(n=22)$ and metastatic serotonin-producing carcinoid patients $(n=23)$. Each $d o t$ represents a subject. Concentrations are expressed as the natural logarithm (ln) of nanomoles per liter units, to obtain normal distributions. Horizontal lines indicate mean concentrations. Mean free serotonin concentrations, measured in platelet-poor plasma, are $4.6 \mathrm{nmol} / \mathrm{L}$ for healthy controls and $60.8 \mathrm{nmol} / \mathrm{L}$ for carcinoid patients. Mean serotonin concentrations in the carcinoids patients are higher than in the healthy controls $(P<0.001)$

\section{Discussion}

This study demonstrates that plasma and urinary serotonin can be measured selective, specific and sensitive with an automated on-line solid-phase extraction-liquid chromatographic method with tandem mass spectrometric detection (XLC-MS/MS). The urinary reference interval was in agreement with previous results [11,25].

The method is based on similar analytical principles as our previously described method for the analysis of the structurally related plasma metanephrines [19]: solid-phase

b

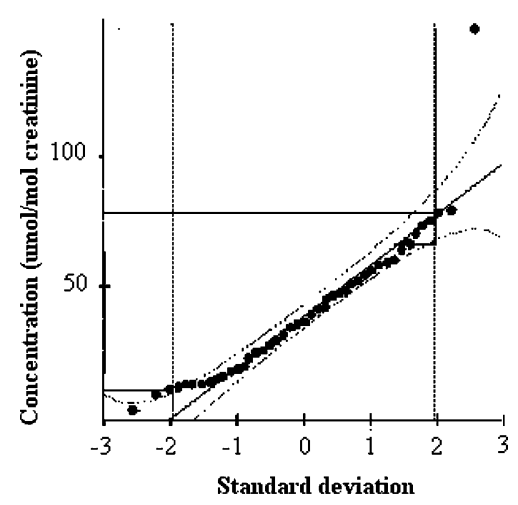

Fig. 3 Distribution of urinary serotonin concentrations in reference samples from 120 healthy individuals in $\mu \mathrm{mol} / \mathrm{mol}$ creatinine. a The distribution of individual serotonin concentrations is shown in a histogram with a mean concentration of $38.2 \mu \mathrm{mol} / \mathrm{mol}$ creatinine.
The black line shows a normal distribution which is in correspondence with the distribution of the individual serotonin concentrations. b Probability plot of the distribution of individual serotonin concentrations indicating normal distribution of the concentrations 
extraction with weak cation exchange followed by hydrophilic interaction chromatography. Major limitations of the regularly used conventional HPLC method with fluorometric detection [26] for the diagnosis of fore- and midgut carcinoid tumors include the long sample preparation time and the use of a non-isotope-labeled internal standard. The newly developed automated method with MS/MS detection is, in addition, more specific because of the selection of the precursor to product mass transition, which enables identification of the analyte. Furthermore, MS/MS allows the use of a stable isotope-labeled internal standard, while time for chromatographic separation can be reduced. Main advantages of the automated sample preparation are ease of handling, portability, and reduction of cost per sample, because of reduced sample preparation time, high throughput, cheaper cartridges, and reuse of cartridges. Furthermore, intraand inter-assay variations are reduced, which increases the reproducibility of results. LC-MS/MS methods without automated sample preparation [27, 28] have sensitivities and specificities that can be compared with the XLC-MS/MS method described here and are increased when compared to conventional HPLC techniques. The supplementary advantage compared to other LC-MS/MS methods is that our method is completely automated, which means a great reduction in total analysis time including sample clean-up. Specific sample preparation chemistry with weak cation exchange for clean-up and chromatographic separation with HILIC result in optimal analysis conditions.

In addition, this study demonstrated that the low physiological serotonin levels in platelet-poor plasma can be routinely measured with a more specific and sensitive method than before [25, 29]. LLOQ for plasma serotonin has been reduced 70 times at our laboratory, enabling measurement of free serotonin in healthy persons. This resulted in a comparison between carcinoid patients and healthy controls with the outcome that in carcinoid patients, free serotonin was 13-fold higher $(P<0.001)$ than in healthy controls. High concentrations can be hazardous in the body and result in heart valve damage and vasoactivity-related symptoms as diarrhea, flushing, and bronchoconstriction [5]. Contamination of the low platelet-poor concentrations with the high platelet-stored amount of serotonin has to be avoided. Therefore, preanalytical factors are of importance for the measurement of serotonin in platelet-poor plasma $[5,24]$ and serotonin levels in this specific blood fraction are not consistent for healthy subjects. Our results for healthy controls are in agreement with those determined with a similar blood sampling and sample pre-treatment method [24], although less careful collection and centrifugation [25] result in higher concentrations. Carcinoid patients have shown elevated concentrations previously, as in our results [25].

In order to investigate the recently uncovered role of serotonin as a peripheral hormone in processes such as liver cell regeneration [4], valvular heart disease [30] and bone formation in laboratory animals $[8,31]$, it will be important to clarify the role of factors influencing the free serotonin fraction. The serotonin transporter, which is responsible for inward transport of free serotonin, shows considerable genetic variation, causing different levels of expression. Commonly prescribed medication such as selective serotonin reuptake inhibitors (SSRIs), influence serotonin availability by interfering with its metabolic clearance and uptake as a consequence of the blocking of the serotonin transporter [6, 32]. The role of serotonin in the development of osteoporosis and bone formation has been associated with the use of those SSRIs [8, 31]. During SSRI use and in patients with osteoporosis free serotonin levels are currently unknown, but should be measured in the future to investigate its role in the development and the treatment of osteoporosis.

\section{Conclusion}

Automated on-line XLC-MS/MS enables the quantification of serotonin in both urine and plasma samples. This method overcomes the limitations of existing manual HPLC procedures, especially with regard to interference and hands on analysis time. Due to the high sensitivity and specificity, low free serotonin levels in platelet-poor plasma can be measured routinely, enabling to investigate its role in serotonin-related disorders.

Acknowledgments We thank Prof. Dr. B.H.R. Wolffenbuttel and LifeLines for providing reference samples and accompanying data.

Open Access This article is distributed under the terms of the Creative Commons Attribution Noncommercial License which permits any noncommercial use, distribution, and reproduction in any medium, provided the original author(s) and source are credited.

\section{References}

1. Tyce GM (1990) J Cardiovasc Pharmacol 16(Suppl 3):S1-S7

2. Young SN, Teff KL (1989) Prog Neuropsychopharmacol Biol Psychiatry 13:373-379

3. Grahame-Smith DG (1988) Q J Med 67:459-466

4. Lesurtel M, Soll C, Graf R, Clavien PA (2008) Cell Mol Life Sci 65:940-952

5. Kema IP, De Vries EG, Muskiet FA (2000) J Chromatogr B Biomed Sci Appl 747:33-48

6. Naughton M, Mulrooney JB, Leonard BE (2000) Hum Psychopharmacol 15:397-415

7. Anderson GM (2002) J Am Acad Child Adolesc Psychiatry 41:1513-1516

8. Rosen CJ (2009) N Engl J Med 360:957-959

9. Meijer WG, Kema IP, Volmer M, Willemse PH, De Vries EG (2000) Clin Chem 46:1588-1596 
10. Kema IP, Willemse PH, De Vries EG (1999) N Engl J Med 341:453-454

11. Kema IP, De Vries EG, Schellings AM, Postmus PE, Muskiet FA (1992) Clin Chem 38:534-540

12. Kema IP, Meijer WG, Meiborg G, Ooms B, Willemse PH, de Vries EG (2001) Clin Chem 47:1811-1820

13. Feldman JM (1986) Clin Chem 32:840-844

14. Onaitis MW, Kirshbom PM, Hayward TZ, Quayle FJ, Feldman JM, Seigler HF, Tyler DS (2000) Ann Surg 232:549-556

15. Kema IP, De Vries EG, Slooff MJ, Biesma B, Muskiet FA (1994) Clin Chem 40:86-95

16. Kema IP, Schellings AM, Hoppenbrouwers CJ, Rutgers HM, De Vries EG, Muskiet FA (1993) Clin Chim Acta 221:143-158

17. Hennion MC (1999) J Chromatogr A 856:3-54

18. Hyotylainen T (2007) J Chromatogr A 1153:14-28

19. de Jong WH, Graham KS, van der Molen JC, Links TP, Morris MR, Ross HA, De Vries EG, Kema IP (2007) Clin Chem 53:1684-1693

20. de Jong WH, Graham KS, De Vries EG, Kema IP (2008) J Chromatogr B Analyt Technol Biomed Life Sci 868:28-33

21. D.G.Rhoads Associates Inc (2007) http://www.dgrhoads.com (Accessed October 2009)
22. CLSI (2000) Approved Guideline-Second Edition 20

23. de Jong WH, de Vries EG, Kema IP (2009) N Engl J Med 360:2580-2581

24. Anderson GM, Feibel FC, Cohen DJ (1987) Life Sci 40:1063-1070

25. Pussard E, Guigueno N, Adam O, Giudicelli JF (1996) Clin Chem 42:1086-1091

26. Kwarts E, Kwarts J, Rutgers H (1984) Ann Clin Biochem 21(Pt 5):425-429

27. Hammad LA, Neely M, Bridge B, Mechref Y (2009) J Sep Sci 32:2369-2376

28. Monaghan PJ, Brown HA, Houghton LA, Keevil BG (2009) J Chromatogr B Analyt Technol Biomed Life Sci 877:2163-2167

29. Hirowatari $Y$, Hara $K$, Kamihata H, Iwasaka T, Takahashi $H$ (2004) Clin Biochem 37:191-197

30. Bhattacharyya S, Schapira AH, Mikhailidis DP, Davar J (2009) Lancet 374:577-585

31. Yadav VK, Ryu JH, Suda N, Tanaka KF, Gingrich JA, Schutz G, Glorieux FH, Chiang CY, Zajac JD, Insogna KL, Mann JJ, Hen R, Ducy P, Karsenty G (2008) Cell 135:825-837

32. Vaswani M, Linda FK, Ramesh S (2003) Prog Neuropsychopharmacol Biol Psychiatry 27:85-102 